\section{International Scientific Journal Theoretical \& Applied Science}

\author{
p-ISSN: 2308-4944 (print) e-ISSN: 2409-0085 (online) \\ Year: $2016 \quad$ Issue: $1 \quad$ Volume: 33 \\ Published: $30.01 .2016 \quad$ http://T-Science.org
}

\author{
Elnur Latif oglu Hasanov \\ Corresponding member of International Academy of \\ Theoretical and Applied Sciences, \\ Ph.D., Senior specialist of Ganja Department \\ Azerbaijan National Academy of Sciences, \\ Ganja, Azerbaijan \\ 1-hasan@hotmail.com
}

SECTION 12. Geology. Anthropology.

Archaeology.

\title{
TYPICAL LOCAL FEATURES OF ARCHITECTURE OF GANJA (ON THE SAMPLE OF IMAMZADE TOMB-COMPLEX OF GANJA)
}

Abstract: In this scientific work basic features of historic-cultural traditions of architecture Ganja have been investigated on the basis of different scientific sources and innovative methods.

Key words: Azerbaijan, historical-ethnographic research, Ganja, architecture.

Language: German

Citation: Hasanov EL (2016) TYPICAL LOCAL FEATURES OF ARCHITECTURE OF GANJA (ON THE SAMPLE OF IMAMZADE TOMB-COMPLEX OF GANJA). ISJ Theoretical \& Applied Science, 01 (33): 1-3.

Soi: http://s-o-i.org/1.1/TAS-01-33-1 Doi: crossef http://dx.doi.org/10.15863/TAS.2016.01.33.1

\section{TYPISCHE LOKALE MERKMALE DER ARCHITEKTUR DES GÄNDSCHÄ (AUF DER PROBE DES GÄNDSCHÄS GRABSTÄTTE `IMAMSADÄ`KOMPLEXEN)}

Die Zusammenfassung: In dieser wissenschaftlichen Arbeit Grundzüge des historisch-kulturellen Traditionen der Gändschä wurden auf der Grundlage von unterschiedlichen wissenschaftlichen Quellen und innovative Methoden untersucht worden.

Schlüsselwörter: Aserbaidschan, historisch-ethnographischen Forschung, Gändschä, Architektur.

Die Einführung

Die Grabstätte Imamsade, die sich im staatlichen historik-kulturellen Naturschutzgebiet befindet in einem der altertümlichen Zentren der Wissenschaft und der Kultur - die Stadt Gändschä.

Die Grabstätte wurde hier im Jahr 739 über dem Grab des Urenkels Propheten Muhammed - des Sohnes von Imam Ali ibn Hussejn, des fünften Imams Muhammed Baqir und seiner Tochter Ummi Hekima - Movlan Ibrahim errichtet. Das Wort "Imamsadä" stammt vom Begriff „Kind des Imams“ und es bedeutet der Nachkomme von Imam.

Unter dem Volk versteht man das Wort „Imamsade“ wie ein heiliger Tempelort.

Während der Herrschaft von Umayyaden (661 750) wurden viele Mitglieder Ahl Al-Bait (Nachkommen von Muhammed) verfolgt und an die Ränder des Amirs verjagt. Movlan Ibrahim ist in die Stadt Gändschä damaliges Zentrum der uralten islamischen Kultur umgezogen.

Movlan Ibrahim siedelte in der Stadt Gändschä und lebte bis seinem Tod hier und wurde auch hier begraben. Zum Ehren seiner Heiligen Persönlichkeit wurde über seinem Grab eine Grabstätte errichtet.

\section{Materialen und Methoden}

Aserbaidschan liegt zwischen Europa und Asien und hat eine günstige natürlich-geographische Konjunktur, mildes Klima, fruchtbare Boden, reiche Bodenschätze. Dieses Territorium ist in der wirklichkeit als erstes Obdach der menschlichen Zivilisation berühmt. Vor zwei Millionen Jahren gab es hier jede Bedingung für die Bewohnung, Leben, Schaffen, Entfaltung und Fortschriff der Urmenschen.

Gändschä ist eine älteste Ecke der Kultur unseres Landes. Gändschä hat eine geschichte mindestens 4000 Yahre des müselmanischen Orients und hier sind alte Baudenkmäler, grabmal des Aposlels, ein wertiges Heiligtum. Dieses wichtige Denkmal liegt 7 kilometr weit vom moderuen Gändschä, am rechten Ufer gändschäflusses. Grabmal İmamsades hält man für die bedeutenden Symbolen der Stadt.

Gändschäs Aposlel grabmal wurde auf das grab des jungen Prinz İbrahim des Sohns des fünften Aposlel Mahammad Bagir, der 739 gefallen war, hinaufgesetzt. Von diesem Denkmal offenbarte sich wichtige historische Quelle der Jahrbuches. Grabmal 
Aposlel wurde am Ende des XIV. und am Anfang des XV. Jahrhundert ganz errichtet. İn den XVIIXVIII Jahrhunderten wurde herum Moschee, Tempel und andere grabmäler erhöht.

Gändschäs İmamsade grabmal war seit Jahrhunderten zum Heiligtum der Muselmanen, die nicht nur aus Aserbaidschan, sondern auch aus anderen Ländern gekommen waren.

Dieses Ort hat sich in einem heiligen Tempel für gläubigen Muslim verwandelt. Die im VIII Jahrhundert über dem Grab von Movlan Ibrahim gebaute Grabstätte, wurde in den XIV - XVI Jahrhunderten vergrößert, in ihrer Gegend liegenden Gebäuden wurden grundsätzlich in XVII - XVIII Jahrhunderten gebaut. Die Grabstätte ist das wertvollste Denkmal im Imamzadeh komplex. Die Höhe der Grabestin ist $12 \mathrm{~m}$, die Kuppelhöhe ist 2,7 $\mathrm{m}$, Durchmesser ist 4,4m. Die Fassadenplatten sind mit blauen Kacheln bedeckt.

Im XX. Jahrhundert wurde die Innenwand des Innenteils der Grabstätte wichtigste historisch epigraphische Muster entdeckt und von den hervorragenden Historikern erforscht - verstorbenen Archäologen, Professor Isak Dshäfzadä, sowie von einer bekannten Wissenschaftlerin,

Akademikerin Mäschädichanym Nemätova wurden untersucht und werden in folgender Weise gelesen: „Er, der Gott ist ewig. Das ist ein Heiligtum, ein Paradiesgarten von Movlan Ibrahim - Sohn des Imams Mohamad Baqir - sei ihm Ehre. 120 Jahre nach dem Tod seines Großvaters ist er gestorben „Sei mit ihm Allahs Segen!“”.

Infolge der wissenschaftlichen Forschung dieser historischen Schrift wurde es bekannt, dass das Denkmal dem Sohn des Imams über seinem Grab in 738-739 errichtet wurde. Das Ort des Heiligtums Imamzadä ist den Vertretern vom hervorragenden Aserbaidschanischen Dichter und Philosoph Nizami Gändschävis Generation - welche Scheychzamanovs Güte gehalten.

Im XIX. Jahrhundert begann im İmamsade grabmal die Restaurationsarbeiten zuerst vom heldenhaften Truppenleiter und Chans Dschavad Chan, danach 1878-1879 unter der Leitung des generals des zweiten Reiter-muselmanischen Regiments der russischen Armee İsrafil baj Yadigarsade.

\section{Schlussfolgerungen und Empfehlungen}

Der Stolz der heroischen Geschichte von Gändschä - der letzte Chan, Dschavad Chan Zijads Sohn (1748 - 1804), auf seine Anweisung wurden große Restaurierungsarbeiten geführt. In den Jahren 1878 - 1879 wurde durch Initiative des Generalmajors Israfil bäy Yadigarzadä und am Anfang des XX. Jahrhunderts aus Initiative einer
Gruppe von Intelligenzen das Altarraum Heiligtum wieder renoviert.

In diesem Heiligtum in dem Imamzadäheiligtum wurden Scheychzamanli - Pischnamazzadä, Mirzä Mehdi Nadschi, Mir Säyyid Abbas Aga - Vertreter von Sazzidsgeneration, General - Major Israfil bay Jadigarzadä und andere bedeutenden Persönlichkeiten begraben.

Das Heiligtum Komplex war jahrhundertelang als Zentrum der Wohltätigkeit für einsame, obdachlose Menschen bekannt. In der ehemaligen UdSSR war nun Imamzadä als muslimischer einzig offenes und funktionierendes Heiligtum. In den 1930 - 1944 Jahren während der sowjetischen Macht wurde von den Hilfsgebäuden Imamzadä Heiligtum als Kinderheim benutzt.

Dieser heilige Ort hatte die vom Krieg gelittenen kleinen Kinder verschiedener Nationen betroffen.

Unser Land, in dem unser größte Lider Hejdär Älijev den Grund der Staatlichen Politik, der Priorität gegründet hatte, hat tiefsten multikulturellem Stamm, Toleranztraditionen und Bewahrung der verschiedenen religiösen, kulturellen und historischen Denkmäler.

Präsident der Souveränen Aserbaidschanischer Republik Ilham Älijev, der Nachfolger von großem Lider setzt die kluge, nationale Politik erfolgreich fort.

Er hatte die religiösen, historischen und architektonischen Denkmälern Wiederherstellung und zahlreichen Erlasse und Verordnungen im Zusammenhang mit der Umstrukturierung ausgegeben, unter der Führung der Präsidentin der Heydar Aliyev-Stiftung, gutwillige Botschafterin UNESCO und ISESCO Frau Mehriban Äliyeva verbringende zahlreiche Projekte ist für unsere nationale und kulturelle

Erben ein unersetzliches Muster. Von Präsidenten Ilham Älijev wurden in den Jahren 20102015 sieben Verordnungen untergeschrieben. Die religiöse und historische Komplex Imamzadeh wurde in Ganjas Architekturstil erheblich umgebaut.

Heute ist Imamzadeh Komplex einer von besten Heiligtümern der islamischen Welt, und nicht nur für zahlreiche einheimische sondern auch für viele ausländische Pilger besuchte heiliger Ort.

Am 1. März 2010, am 30. Dezember 2011, am 5. Juni 2013, am 16. Mai 2014, am 5. November, am 9. April und am 9. Septembre 2015 hat der Präsident der Aserbaidschanischen Republik Heer İlham Aliyev für die Restauration, Wohlordnung und Einrichtungsarbeiten des İmamsade grabmals komplex, das in der gegend Gändschäs Staatlichen Schonung der geschichte und Kultur liegt, eine Anordnung getroffen. 


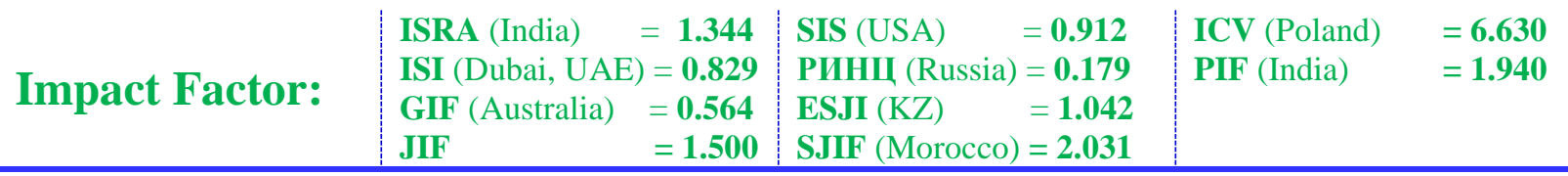

\section{References:}

1. Azərbaycan arxeologiyası (2008): 6 cilddə, VI cild. Bakı: Şərq-Qərb nəşriyyatı, 632 p.

2. Azərbaycan etnoqrafiyası (2007): 3 cilddə, I cild, Bak1: Şərq-Qərb, 544 p.

3. Guliyeva NM Hasanov EL (2013) Investigation of basic decorative-applied arts of Ganja on the basis of some innovative arguments and technologies. Science and Society: Proceedings of the 3rd International scientific-practical conference. - London: SCIEURO (Great Britain), pp. 281-291.

4. Guliyeva NM, Häsänov EL (2014) Die traditionelle Gändschänischen Teppiche von Zeitraum der Aserbaidschanischen Gelehrten und Dichter Mirsä Schäfi Waseh als ethnoanthropologische quelle (XIX Jahrhundert). European Applied Sciences, 2, pp. 3-5.

5. Həsənov EL (2012) Gəncə İmamzadə türbəsi (tarixi-etnoqrafik tədqiqat). 1-ci nəşr. Bakı: Elm və təhsil, $268 \mathrm{p}$.

6. Hasanov EL (2014) Innovative basis of research of local handicraft branches of Ganja of the second half of XIX - beginning of XX centuries. Mediterranean Journal of Social Sciences, vol. 5, № 23, Part IV, pp. 2359-2362. Doi:10.5901/mjss.2014.v5n23p2359

7. Ofəndiyev RS (1976) Azərbaycanın dekorativtətbiqi sənətləri. Bakı: İşıq.

8. Ohmədov FM (2007) Gəncənin tarix yaddaşı. Gəncə: Elm.

9. Gəncənin məhəllə adları (1978) Elm və həyat jurnal1, №10.

10. Hasanov EL (2015) Multidisciplinary approach to investigation of the basic handicraft branches of Ganja till the XX century. ISJ Theoretical \& Applied Science 1(21): 7-15. DOI: http://dx.doi.org/10.15863/TAS.2015.01.21.2
11. Hasanov EL (2015) To the Question on Research of Craftsmanship Traditions of Ganja of XIX - First Half of XX Centuries. Mediterranean Journal of Social Sciences, vol. 6, № 1, Part S1, pp. 433-437. Doi:10.5901/mjss.2015.v6n1s1p433

12. Həmidova İ (2000) Azərbaycan parça sənətinin tarixi inkişaf yolları. Elmi axtarışlar, VIII toplu, Bak1.

13. Həsənov EL (2015) Gəncə İmamzadə türbəsi ənənəvi multikulturalizm abidəsi kimi. Qafqazda mədəni-dini irsin qorunması mövzusunda beynəlxalq konfransın materialları. Bak1, 2015, pp. 117-120.

14. Həvilov HA (1991) Azərbaycan etnoqrafiyası. Bakı: Elm.

15. Гасанов ЭЛ (2015) Об инновационных результатах историко-этнографического исследования художественной керамики древней Гянджи. Новый университет Актуальные проблемы гуманитарных и общественных наук. № 8-9 (53-54). DOI: 10.15350/2222-1484.2015.8-9

16. Məmmədov FN (1976) XIX əsrdə Gəncə şəhərinin ərazisi, əhalisi və idarəsi (1868-ci ilə qədər). Azərbaycan SSR Elmlər Akademiyasının Xəbərləri (Tarix, fəlsəfə və hüquq seriyas1), №3, pp. 30-37.

17. Mustafayev A (2001) Azərbaycanda sənətkarlıq. Bak1: Altay.

18. Smith WB, Hasanov EL (2013) Importance of handicraft traditions in investigation of history of urban culture in Ganja. ISJ Theoretical \& Applied Science 11(7): 61-66. doi: http://dx.doi.org/10.15863/TAS.2013.11.7.10

19. Tərlanov M, Ofəndiyev R (1960) Azərbaycan xalq sənəti. Bakı: Uşaq gənc nəşr.

20. The dawn of Art. (1974) Leningrad: Aurora Art Publishers, $196 \mathrm{p}$.

Elnur Lätif oglu Häsänow

Die Aserbaidschanische Nationale Wissenschaftliche Akademie

Die Gändschänischen Wissenschaftlichen Abteilung (Filiale), Vorgesetzte Spezialist, Korrespondierendes Mitglied der Internationalen Akademie der theoretischen und angewandten Wissenschaften

Gändschä, Aserbaidschan 1-hasan@hotmail.com 